\title{
Super-Twisting Algorithm Second-Order Sliding Mode Control for a Synchronous Reluctance Motor Speed Drive
}

\author{
Wen-Bin Lin ${ }^{1}$ and Huann-Keng Chiang ${ }^{2}$ \\ ${ }^{1}$ Graduate School of Engineering Science \& Technology, National Yunlin University of Science \& Technology, No. 123, \\ University Road, Section 3, Douliou, Yunlin 64002, Taiwan \\ ${ }^{2}$ Department of Electrical Engineering, National Yunlin University of Science \& Technology, No. 123, University Road, \\ Section 3, Douliou, Yunlin 64002, Taiwan \\ Correspondence should be addressed to Huann-Keng Chiang; chianghk@yuntech.edu.tw
}

Received 30 April 2013; Accepted 18 June 2013

Academic Editor: Yuqiang Wu

Copyright (C) 2013 W.-B. Lin and H.-K. Chiang. This is an open access article distributed under the Creative Commons Attribution License, which permits unrestricted use, distribution, and reproduction in any medium, provided the original work is properly cited.

\begin{abstract}
This paper presents the design and implementation of a super-twisting algorithm second-order sliding mode controller (SOSMC) for a synchronous reluctance motor. SOSMC is an effective tool for the control of uncertain nonlinear systems since it overcomes the main drawbacks of conventional sliding mode control, that is, large control effort and chattering. The practical implementation of SOSMC has simple control laws and assures an improvement in sliding accuracy with respect to conventional sliding mode control. This paper proposes a control scheme based on super-twisting algorithm SOSMC. The SOSMC is mathematically derived, and its performance is verified by simulation and experiments. The proposed SOSMC is robust against motor parameter variation and mitigates chattering.
\end{abstract}

\section{Introduction}

Synchronous reluctance motors (SynRMs) $[1,2]$ have been used as drive sources for many years but are regarded as dynamically inferior to synchronous and induction motors. SynRMs have a mechanically simple and robust structure. They can thus be used in high-speed and high-temperature environments. Interest in SynRMs has increased the applications of high-performance AC drives [3-7]. The rotor circuit of SynRMs is open circuit, so the flux linkage of SynRMs is directly proportional to the stator currents; the torque of SynRMs can be controlled by adjusting the stator currents.

There has been renewed interest in SynRM vector control that utilizes the transformation method of the reference frame. This paper adopts the maximum torque control (MTC) strategy of a constant current angle, which allows the motor to operate under conditions that produce the maximum torque per current [8].

A fast error-free dynamic response is a primary concern in control systems. Practical servo systems have parameter variations and external load disturbances. In order to overcome uncertainty, sliding mode control (SMC) $[9,10]$ was developed. SMC is an effective and robust technology for parameter variation and external disturbance rejection. It has been applied to robot and motor control [9-12]. SMC is a robust for nonlinear systems. Discontinuous systems require an infinite switching frequency. Therefore, reducing chattering is very important for SMC. Second-order SMC (SOSMC) $[12,13]$ is robust against model uncertainties and external disturbances, while mitigating chattering. However, few studies have been conducted on SOSMC for SynRMs.

Fuzzy-control schemes also have been proven to be very effective techniques in the field of complex ill-defined nonlinear systems in the past few decades, particularly those possessing a high degree of uncertainty and nonlinearity. Recently, fuzzy controllers with complex adaptive algorithms have been expansive to nonlinear multiple-input-multipleoutput (MIMO) systems $[14,15]$. Controllers in these adaptive control schemes are generally composed of two main elements. The first is a fuzzy system, which performs as 
an approximator to accomplish feedback cancellation. The second element is a robust compensator, such as slidingmode control (SMC) [14], that controls parameter tuning in the fuzzy system and assures stability according to Lyapunov's method. These means have been successful in using robust control schemes to guarantee system stability. However, specific constrained conditions should be assumed in the control processes, for example, approximation errors and lumped uncertainties are bounded, and the bounds are known. Many hybrid control techniques [15] combining various control elements have been developed to conquer the influence of external disturbances and approximation errors. Though this approach accomplishes favorable tracking performance, the number of fuzzy rules in the control process increases considerably, when the nonlinear systems exhibit more degrees of freedom. This conducts to a heavy computational load and increases the difficulty associated with real-time implementation.

Unlike conventional first-order SMC, SOSMC belongs to higher-order sliding mode (HOSM). Levant [13] determined the relationship between accuracy and sampling time for HOSM. Bartolini et al. [16] tested five control methods of HOSM. They found that HOSM has simple construction and is robust against system structure variability.

Rashed et al. [17] developed sensorless super-twisting SOSMC speed and flux control for a voltage-fed inductionmotor drive. Experimental results verified the system robustness, with no chattering or steady-state errors. Kunusch et al. [18] applied super-twisting SOSMC for polymer electrolyte membrane (PEM) fuel cell stack breathing control and verified the results by simulation. Tournes and Shtessel [19] combined super-twisting and minimal-time (bang-bang) control for automatic docking. Computer simulations showed that the design achieves excellent performance when faced with parameters variation. Reference [20] explored Lyapunovdesigned super-twisting sliding mode control strategy to maximize the energy production of a wind energy conversion system (WECS) simultaneously reducing the mechanical stress on the shaft. Reference [21] presented super-twisting algorithm-based sliding mode controller for a refrigeration system and showed much more robustness at external noise in numerical simulation. Reference [22] applied supertwisting sensorless control for the stator current observer design of permanent magnet synchronous motors in numerical simulation. Reference [23] adopted super-twisting sliding mode controller as a reduced order observer of the rotor fluxes estimation for synchronous motors in numerical simulation. Levant proved finite-time convergence using pointto-point method for state trajectories [24, 25], Lyapunov function was found and analyzed in [26, 27], and Lyapunov function with finite convergence time as a solution to partial differential equation was offered in [28, 29]. Reference [30] performed the analysis in time domain directly.

Only two studies $[31,32]$ have applied SOSMC to SynRM control. Mohamadian et al. [31] used suboptimal SOSMC. Chiang et al. [32] used super-twisting SOSMC in simulations. Hence, this paper proposes a control scheme based on supertwisting SOSMC that is verified by experiments.
The rest of this paper is organized as follows. SynRM modeling in the synchronously rotating rotor reference frame is discussed in Section 2. In Section 3, the vector control of SynRM is introduced. In Section 4, the integral variable structure speed controller is described. In Section 5, the supertwisting algorithm SOSMC is derived. The proposed speed controller is implemented using a PC-based SynRM drive. In Section 6, experimental results show that the proposed super-twisting algorithm SOSMC controller provides highperformance dynamic characteristics and robustness against parameter variation and external load disturbances. Finally, conclusions are presented in Section 7.

\section{SYNRM Modeling}

For analysis, the three-phase fixed $a-b-c$ frame of reference in the stator can be converted into a synchronously rotating rotor reference frame using Park's transformation. The $d$ $q$ equivalent circuit of the ideal SynRM model is shown in Figure 1. The corresponding equations are

$$
\begin{aligned}
& V_{d s}=R_{s} i_{d s}+L_{d s} \frac{d i_{d s}}{d t}-\omega_{r} L_{q s} i_{q s}, \\
& V_{q s}=R_{s} i_{q s}+L_{q s} \frac{d i_{q s}}{d t}+\omega_{r} L_{d s} i_{d s} .
\end{aligned}
$$

The corresponding electromagnetic torque $T_{e}$ is

$$
T_{e}=\frac{3}{4} P_{\text {ole }}\left(L_{d s}-L_{q s}\right) i_{d s} i_{q s}
$$

The corresponding motor dynamic equation is

$$
T_{e}-T_{L}=J_{m} \frac{d \omega_{r}}{d t}+B_{m} \omega_{r}
$$

where $V_{d s}$ and $V_{q s}$ are the direct axis ( $d$ axis) and quadrature axis ( $q$ axis) terminal voltages, respectively; $i_{d s}$ and $i_{q s}$ are, respectively, the direct axis and quadrature axis terminal currents or the torque producing current; $L_{d s}$ and $L_{q s}$ are the direct axis and quadrature axis magnetizing inductances, respectively; $R_{s}$ is the stator resistance; and $\omega_{r}$ is the speed of the rotor. $P_{\text {ole }}, T_{L}, J_{m}$, and $B_{m}$ are the poles, the torque load, the inertia moment of the rotor, and the viscous friction coefficient, respectively.

\section{SYNRM Vector Control}

Vector control utilizes the transformation method of the reference frame. It can transform the $a-b-c$ axis fixed reference frame into the $d-q$ axis synchronously rotating reference frame. For an AC motor, the output torque of a SynRM can be adjusted by controlling the currents of the $d$ axis and $q$ axis appropriately.

This paper adopts the MTC strategy [33]. Let current angle $\phi=\tan ^{-1}\left(i_{q s} / i_{d s}\right)$. The maximum torque current angle 


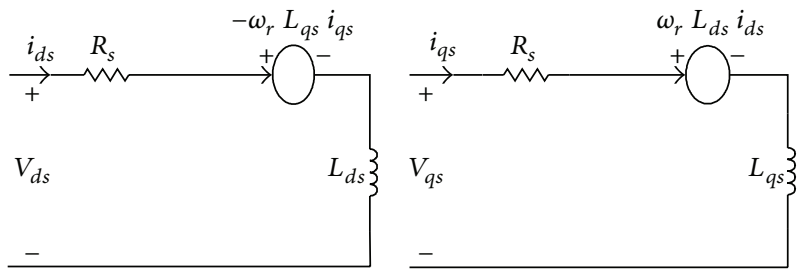

FIgURE 1: $d-q$ axis equivalent circuit of a SynRM.

$\phi$ for the MTC strategy is $\phi= \pm \pi / 4$. The torque current commands are

$$
\begin{gathered}
i_{d s}^{*}=\sqrt{\frac{\left|T_{e}\right|}{(3 / 8) P_{\text {ole }}\left(L_{d}-L_{q}\right)}} \cos \left(\frac{\pi}{4}\right), \\
i_{q s}^{*}=\operatorname{sgn}\left(T_{e}\right) \sqrt{\frac{\left|T_{e}\right|}{(3 / 8) P_{\text {ole }}\left(L_{d}-L_{q}\right)}} \sin \left(\frac{\pi}{4}\right) .
\end{gathered}
$$

\section{Integral Variable Structure Sliding Mode Controller}

Motor dynamics equation (3) can be rewritten as

$$
\begin{aligned}
\frac{d \omega_{r}}{d t} & =\left(-\frac{B_{m}}{J_{m}}\right) \omega_{r}+\frac{1}{J}\left(T_{e}-T_{L}\right) \\
& =a \omega_{r}+b\left(T_{e}-T_{L}\right) \\
& =\left(a_{o}+\Delta a\right) \omega_{r}+\left(b_{o}+\Delta b\right)\left(T_{e}-T_{L}\right), \\
& =a_{o} \omega_{r}+b_{o}(u+f)
\end{aligned}
$$

where

$$
\begin{gathered}
a \equiv-\frac{B}{J}=a_{o}+\Delta a \\
b \equiv \frac{1}{J}=b_{o}+\Delta b \\
u \equiv T_{e}, \\
f \equiv \frac{1}{b_{o}}\left(\Delta a \omega_{r}+\Delta b u(t)-b T_{L}\right), \\
J_{m} \equiv J_{o}+\Delta J \\
B_{m} \equiv B_{o}+\Delta B .
\end{gathered}
$$

The subscript index " $O$ " indicates the nominal system value, " $\Delta$ " represents uncertainty, and $f$ represents the lumped uncertainties.

Define the velocity error as $e(t)=\omega_{r}^{*}-\omega_{r}$, where $\omega_{r}^{*}$ is the velocity command. The velocity error differential equation of a SynRM can be expressed as

$$
\frac{d e(t)}{d t}=\frac{d \omega_{r}^{*}}{d t}-\frac{d \omega_{r}}{d t}=\dot{\omega}_{r}^{*}-a_{o} \omega_{r}-b_{o}[u(t)+f] .
$$

The sliding function $S$ is combined with the integration of the error as follows:

$$
S=e(t)+c \int_{-\infty}^{t} e(\tau) d \tau, \quad c>0 .
$$

The input control $u(t)$ (the electromagnetic torque $T_{e}$ ) can be defined as

$$
u(t)=u_{e q}(t)+u_{n}(t)
$$

where $u_{e q}(t)$ is used to control the overall behavior of the system and $u_{n}(t)$ is used to suppress parameter uncertainties and to reject disturbances. After mathematical manipulation, the overall control $u(t)$ is obtained as $[34,35]$

$$
u(t)=\frac{1}{b_{o}}\left[\dot{\omega}_{r}^{*}-a_{o} \omega_{r}+c e(t)\right]+\left(K+\frac{\eta}{b_{o}}\right) \operatorname{sgn}(S),
$$

where $|f| \leq K$ and $\eta$ is a positive constant.

\section{Super-Twisting Algorithm Second-Order Sliding Mode Controller}

In conventional SMC design, the control target is to move the system state into sliding surfaces $S=0$. SOSMC aims for $S=\dot{S}=0$. That is, the system states converge to zero at the intersection of $S$ and $\dot{S}$ in the state space.

The super-twisting algorithm has been developed for the case of systems with relative degree one in order to avoid chattering in variable structure systems (VSSs) [11]. The state trajectory of the $S$ and $\dot{S}$ phase plane is shown in Figure 2. It twists and approaches the origin on the state space. Finally, it converges to the origin of the phase plane.

Consider sliding variable dynamics given by a system with a relative degree of two:

$$
\dot{y}_{1}(t)=\varphi_{\mathrm{ST}}\left(y_{1}, t\right)+\gamma_{\mathrm{ST}}\left(y_{1}, t\right) u_{\mathrm{ST}}(t),
$$

where $y_{1}(t)$ is the sliding function $S$, in which $\varphi_{\mathrm{ST}}$ and $\gamma_{\mathrm{ST}}$ are uncertain functions with the upper and lower bounds of (12), and $u_{\mathrm{ST}}(t)$ is the scalar control input.

$$
\begin{gathered}
\left|\varphi_{\mathrm{ST}}\right| \leq \Phi_{\mathrm{ST}}, \\
0<\Gamma_{m \mathrm{ST}} \leq \gamma_{\mathrm{ST}} \leq \Gamma_{M S \mathrm{~T}} .
\end{gathered}
$$

The control $u_{\mathrm{ST}}(t)$ can be given as a sum of two components $[13,16]$ :

$$
u_{\mathrm{ST}}(t)=u_{1}(t)+u_{2}(t)
$$

where

$$
\begin{gathered}
\dot{u}_{1}(t)= \begin{cases}-u_{\mathrm{ST}}, & \text { if }\left|u_{\mathrm{ST}}\right|>U, \\
-W \operatorname{sgn}\left(y_{1}\right), & \text { if }\left|u_{\mathrm{ST}}\right| \leq U,\end{cases} \\
u_{2}(t)= \begin{cases}-\lambda\left|S_{0}\right|^{\rho} \operatorname{sgn}\left(y_{1}\right), & \text { if }\left|y_{1}\right|>S_{0}, \\
-\lambda\left|y_{1}\right|^{\rho} \operatorname{sgn}\left(y_{1}\right), & \text { if }\left|y_{1}\right| \leq S_{0},\end{cases}
\end{gathered}
$$

where $U$ is the control value boundary and $S_{0}$ is a boundary layer around the sliding surface $S$. 


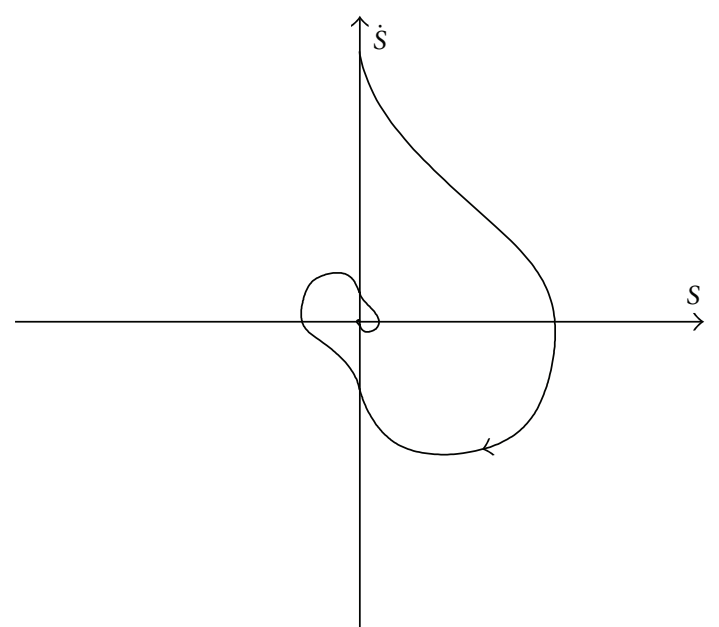

FIGURE 2: Phase plane trajectory of super-twisting algorithm. [13]

The sufficient condition of limited time convergence is

$$
\begin{gathered}
W>\frac{\Phi_{\mathrm{ST}}}{\Gamma_{m S \mathrm{~T}}}, \\
\lambda^{2} \geq \frac{4 \Phi_{\mathrm{ST}}}{\Gamma_{m \mathrm{ST}}^{2}} \frac{\Gamma_{M S \mathrm{~T}}\left(W+\Phi_{\mathrm{ST}}\right)}{\Gamma_{m S \mathrm{~T}}\left(W-\Phi_{\mathrm{ST}}\right)}, \\
0<\rho \leq 0.5 .
\end{gathered}
$$

Equation (3) can be rewritten as

$$
\frac{d \omega_{r}}{d t}=\frac{1}{J_{m}}\left(T_{e}-T_{L}-B_{m} \omega_{r}\right) .
$$

The state variable is defined as

$$
\begin{aligned}
& x_{1}(t)=\int_{-\infty}^{t} x_{2}(\tau) d \tau, \\
& x_{2}(t)=e(t)=\omega_{r}^{*}-\omega_{r} .
\end{aligned}
$$

The initial value of integration $x_{1}\left(t_{0}\right)$ can be expressed as

$$
x_{1}\left(t_{0}\right)=\int_{-\infty}^{t_{0}} x_{2}(\tau) d \tau=\frac{\omega_{r}-\omega_{r}^{*}}{c} .
$$

Then, the system state equation of a SynRM can be expressed as

$$
\begin{gathered}
\dot{x}_{1}=x_{2}, \\
\dot{x}_{2}=\dot{\omega}_{r}^{*}-\frac{B_{m}}{J_{m}} x_{2}+\frac{1}{J_{m}} T_{L}+\frac{B_{m}}{J_{m}} \omega_{r}^{*}+u_{\mathrm{ST}}(t) .
\end{gathered}
$$

Sliding function $y_{1}$ is defined as

$$
y_{1}=x_{2}+c x_{1} .
$$

Then, the system equation can be expressed as

$$
\dot{y}_{1}=\dot{\omega}_{r}^{*}+\left(-\frac{B_{m}}{J_{m}}+c\right) x_{2}+\frac{1}{J_{m}} T_{L}+\frac{B_{m}}{J_{m}} \omega_{r}^{*}+u_{\mathrm{ST}}(t),
$$

where

$$
\begin{gathered}
\varphi(\cdot)=\dot{\omega}_{r}^{*}+\left(-\frac{B_{m}}{J_{m}}+c\right) x_{2}+\frac{1}{J_{m}} T_{L}+\frac{B_{m}}{J_{m}} \omega_{r}^{*}, \\
\gamma(\cdot)=1, \\
u_{\mathrm{ST}}(t)=-\frac{1}{J_{m}} T_{e} .
\end{gathered}
$$

It satisfies the conditions:

$$
\begin{gathered}
B_{\min } \leq B_{m} \leq B_{\max } \\
J_{\min } \leq J_{m} \leq J_{\max } \\
\left|\dot{\omega}_{r}^{*}\right| \leq \dot{\omega}_{r \max }^{*}, \\
\left|\omega_{r}^{*}\right| \leq \omega_{r \max }^{*}, \\
\left|\omega_{r}\right| \leq \omega_{r \max }, \\
\left|T_{L}\right| \leq T_{L \max } .
\end{gathered}
$$

According to (22), the practical controllable signal $T_{e}$ of a SynRM is a continuous controllable signal, which mitigates the chattering.

\section{Simulation and Experimental Results}

A block diagram of the experimental SynRM drive and the super-twisting algorithm SOSMC speed control block diagram of the SynRM servo drive are shown in Figure 3. This system has a hardware drive circuit, a SynRM, mechanical loads, and auxiliary circuitry for control and measurement. The controller was implemented using a DS1104 controller board (dSPACE, Inc., Germany) with a fixed-point DSP TMS320F240. DS1104 is designed for a standard PC environment. The synchronous reluctance motor modeled in this paper is a $0.37 \mathrm{~kW}, 2$-pole, $230 \mathrm{~V}, 4.7 \mathrm{~A}, 60 \mathrm{~Hz}$, and $3600 \mathrm{rpm}$ machine. The machine parameters are as follows: (1) stator resistance $R_{s}=4.2 \Omega$, (2) direct axis magnetizing inductance $L_{d s}=328 \mathrm{mH}$, (3) quadrature axis magnetizing inductance $L_{q s}=181 \mathrm{mH}$, (4) rotor inertia $J_{m}=0.00076 \mathrm{Kg}-\mathrm{m}^{2}$, and (5) friction coefficient $B_{m}=0.00012 \mathrm{Nt}-\mathrm{m} / \mathrm{rad} / \mathrm{sec}$.

Figure 4 is the simulation and experimental responses of SMC velocity and control signal for command $\omega_{r}^{*}=600 \mathrm{rpm}$ under no machine load in nominal case motor inertia and friction coefficient. Figure 5 is the simulation and experimental responses of SOSMC velocity and control signal for command $\omega_{r}^{*}=600 \mathrm{rpm}$ under no machine load in nominal case motor inertia and friction coefficient. From Figures 4 and 5, the proposed SOSMC mitigates the chattering drawback of SMC apparently. Figure 6 is the simulation and experimental responses of SOSMC velocity and control signal for $\omega_{r}^{*}=600 \mathrm{rpm}$ under a $0.3 \mathrm{Nt}-\mathrm{m}$ machine load at the beginning and a $0.9 \mathrm{Nt}-\mathrm{m}$ machine load at 3 seconds in the nominal case motor inertia and friction coefficient. Figure 7 is the simulation and experimental responses of SOSMC velocity and control signal for $\omega_{r}^{*}=600 \mathrm{rpm}$ under a $0.3 \mathrm{Nt}$ $\mathrm{m}$ machine load at the beginning and a $0.9 \mathrm{Nt}-\mathrm{m}$ machine 


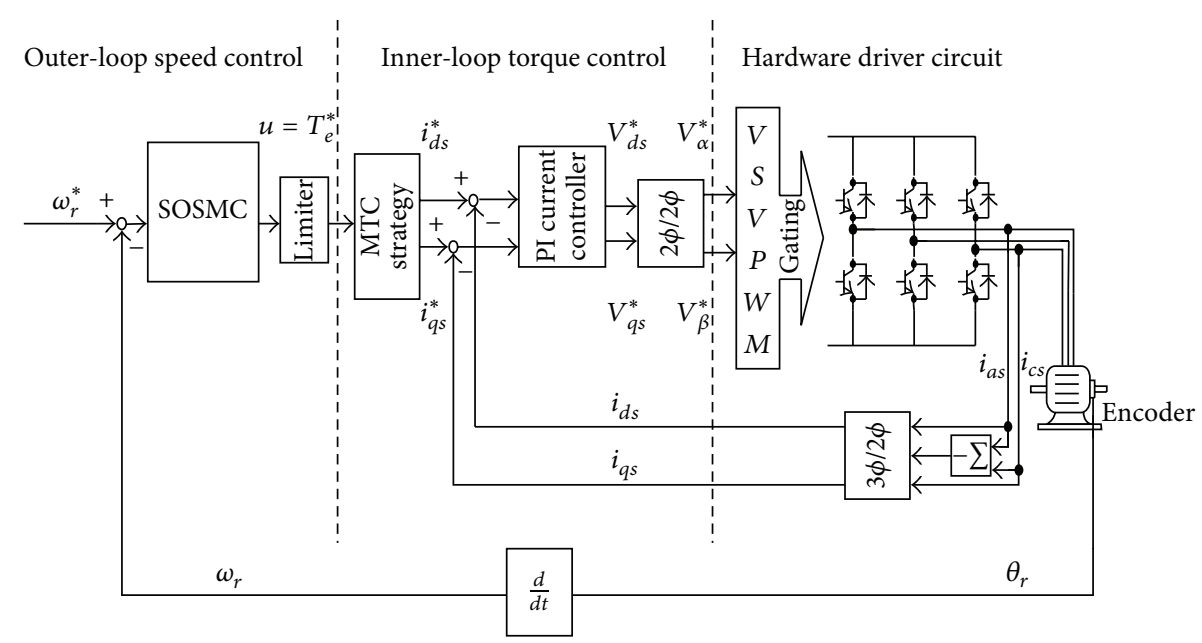

FIGURE 3: Super-twisting SOSMC speed control block diagram of SynRM servo drive.

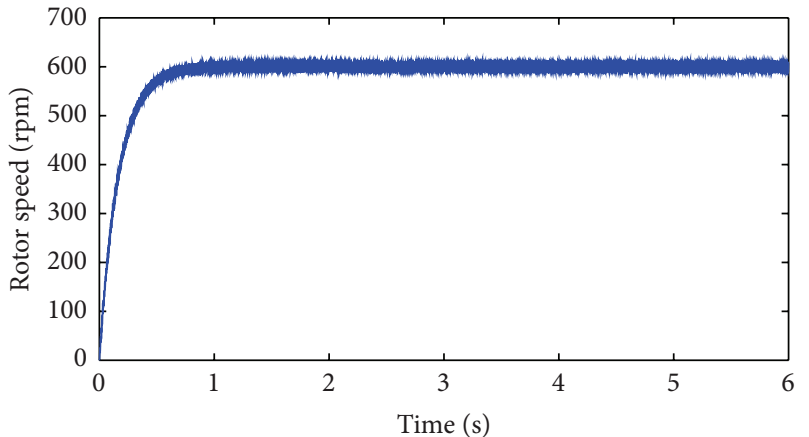

(a)

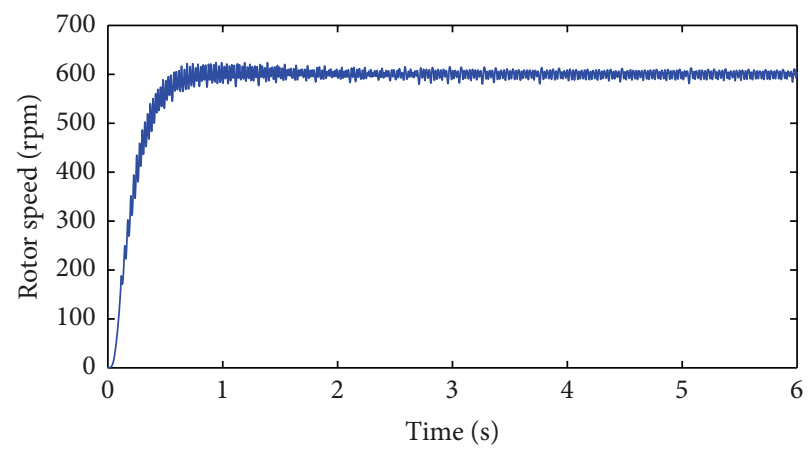

(c)

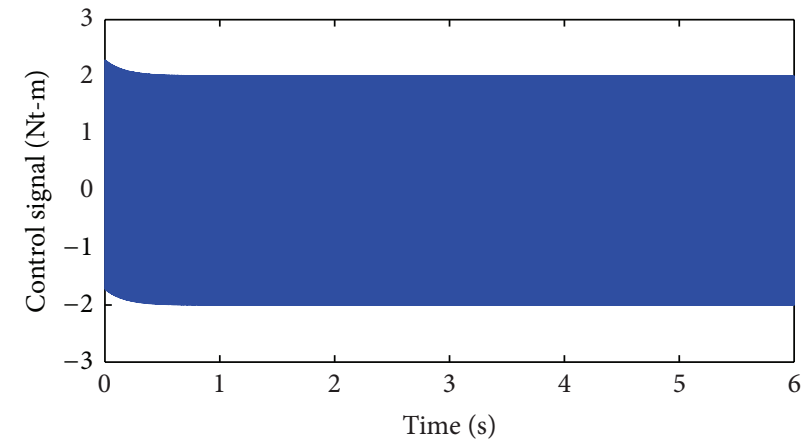

(b)

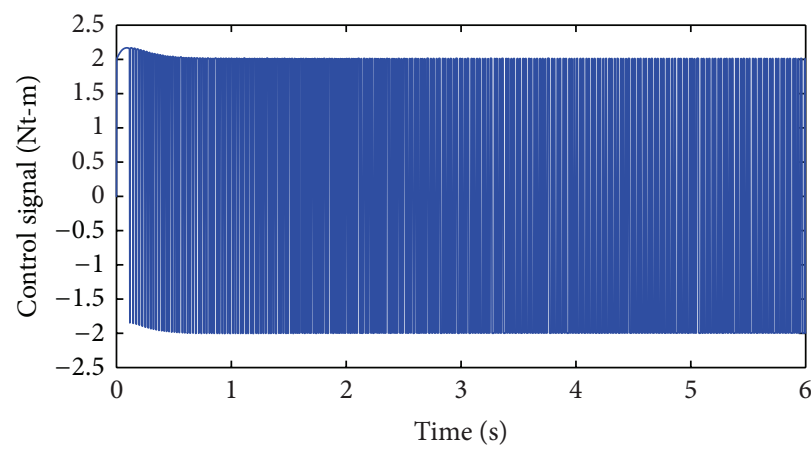

(d)

FIGURE 4: Experimental results of SMC for $\omega_{r}^{*}=600 \mathrm{rpm}$ under no machine load in nominal case of motor inertia and friction coefficient. (a) Rotor velocity response in simulation, (b) control signal response simulation, (c) rotor velocity experiment response, and (d) control signal experiment response.

load at 3 seconds in the 0.5 times nominal case of motor inertia and friction coefficient. Figure 8 is the simulation and experimental responses of SOSMC velocity and control signal for $\omega_{r}^{*}=600 \mathrm{rpm}$ under a $0.3 \mathrm{Nt}-\mathrm{m}$ machine load at the beginning and a $0.9 \mathrm{Nt}-\mathrm{m}$ machine load at 3 seconds in the 2 times nominal case of motor inertia and friction coefficient. From Figures 6 to 8, the proposed SOSMC is robust against motor parameter variation and external disturbances.

\section{Conclusions}

A super-twisting algorithm SOSMC design for robust stabilization and disturbance rejection of a SynRM drive was proposed. The simulation results show good performance for SOSMC under uncertain load subject to variations in inertia and system friction. There is no need for acceleration feedback. An experimental setup was prepared to assess 


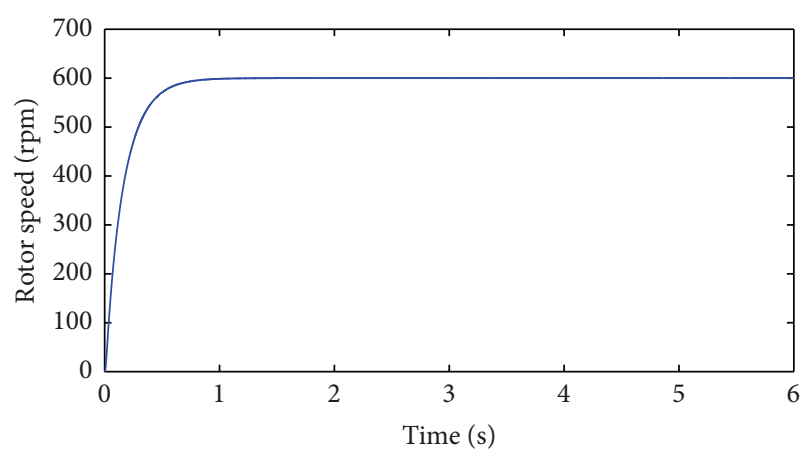

(a)

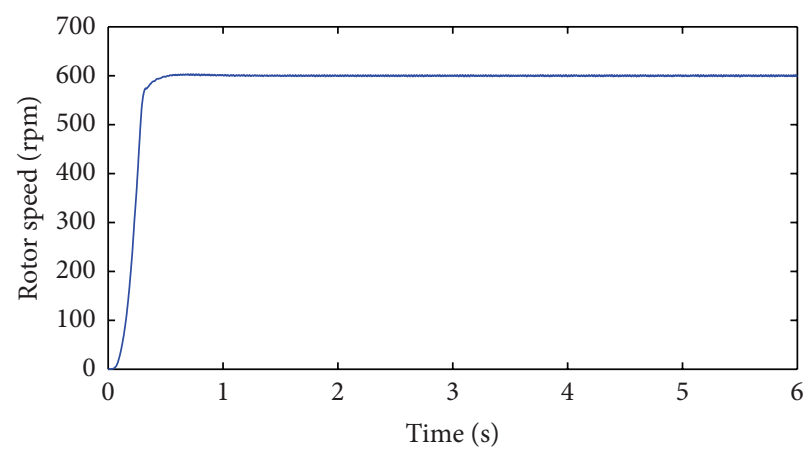

(c)

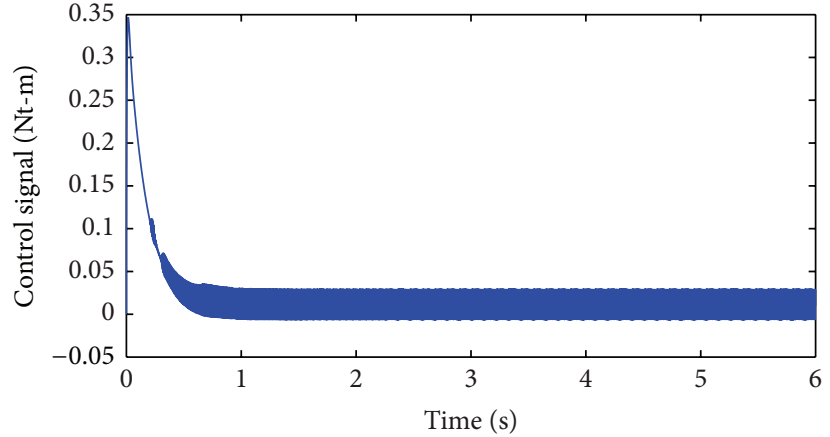

(b)

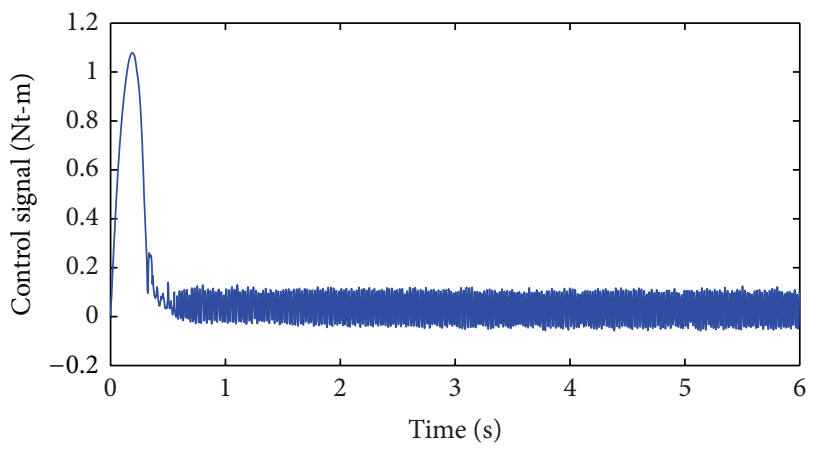

(d)

FIGURE 5: Experimental results of super-twisting algorithm SOSMC for $\omega_{r}^{*}=600 \mathrm{rpm}$ under no machine load in the nominal case of motor inertia and friction coefficient. (a) Rotor velocity response in simulation, (b) control signal response in simulation, (c) rotor velocity experiment response, and (d) control signal experiment response.

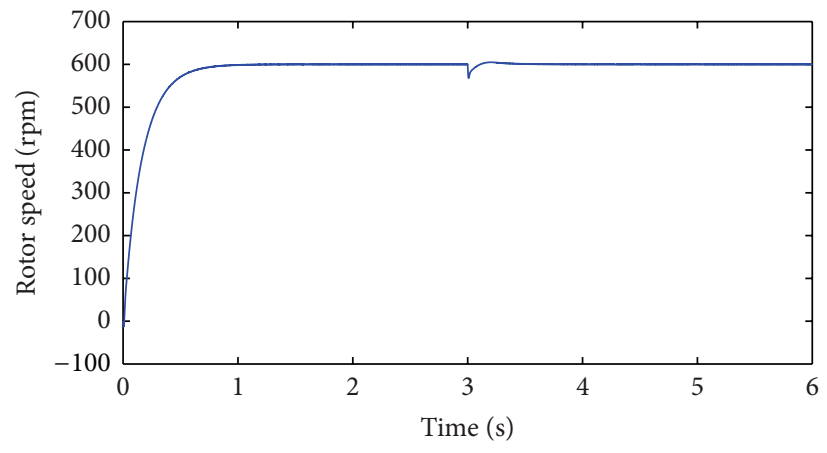

(a)

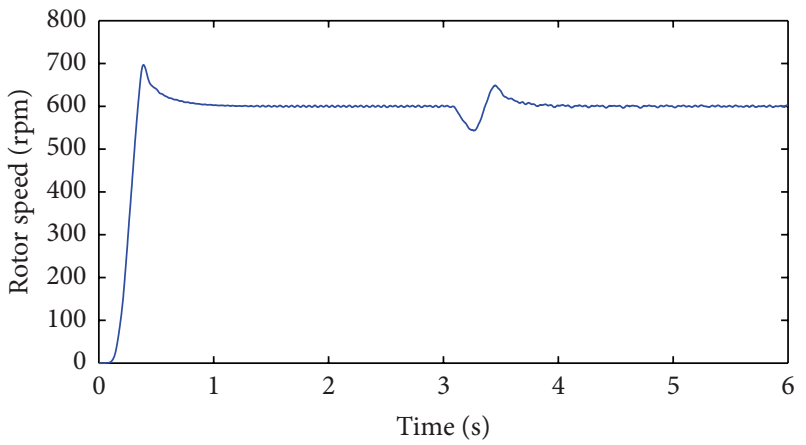

(c)

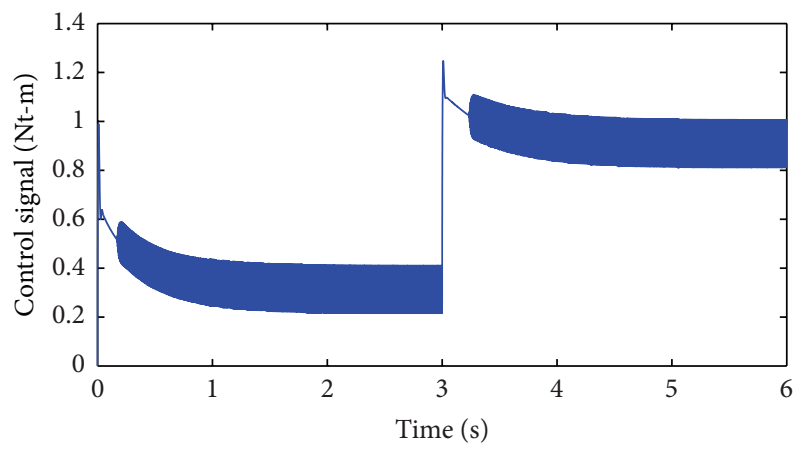

(b)

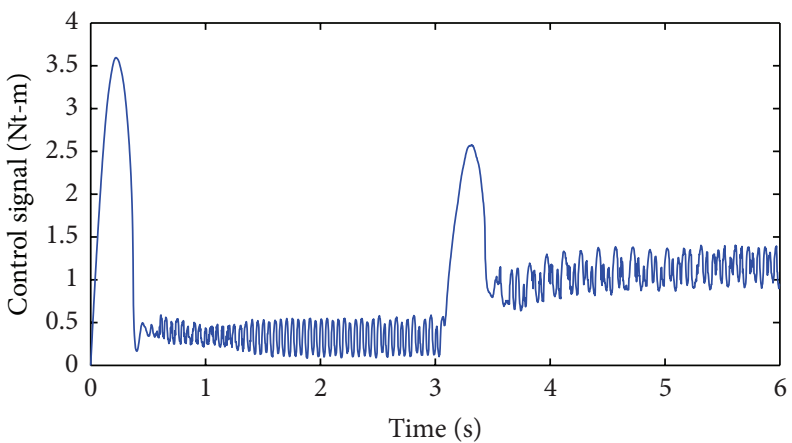

(d)

FIGURE 6: Experimental results of super-twisting algorithm SOSMC for $\omega_{r}^{*}=600 \mathrm{rpm}$ under a $0.3 \mathrm{Nt}-\mathrm{m}$ machine load at the beginning and a $0.9 \mathrm{Nt}-\mathrm{m}$ machine load at 3 seconds in the nominal case of motor inertia and friction coefficient. (a) Rotor velocity response in simulation, (b) control signal response in simulation, (c) rotor velocity experiment response, and (d) control signal experiment response. 


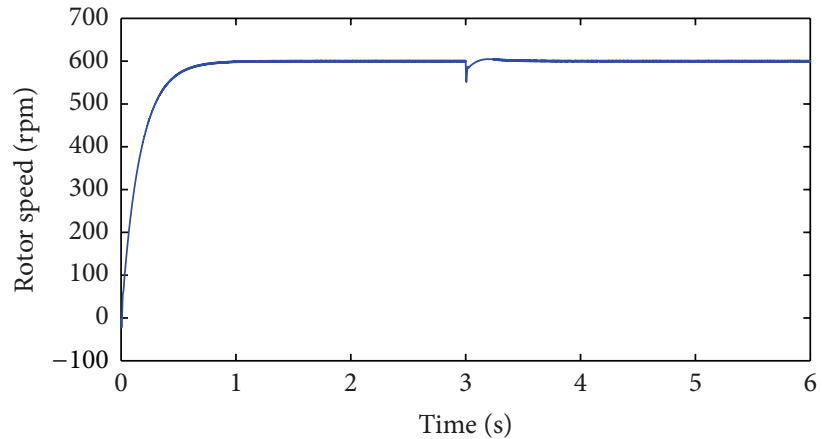

(a)

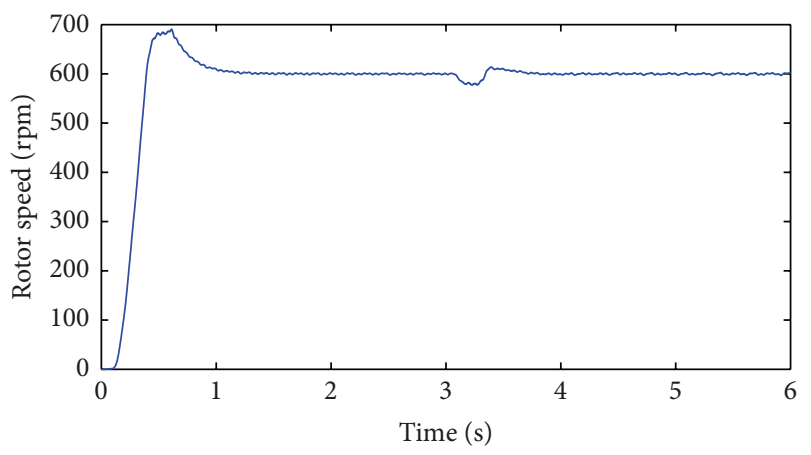

(c)

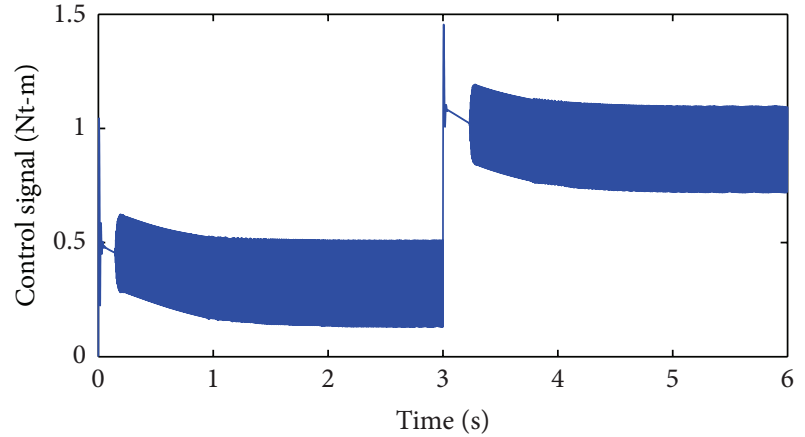

(b)

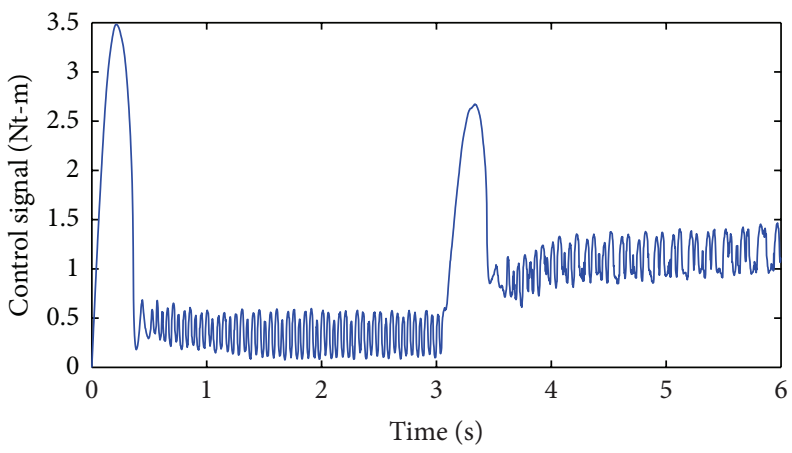

(d)

FIGURE 7: Experimental results of the super-twisting algorithm SOSMC for $\omega_{r}^{*}=600 \mathrm{rpm}$ under a $0.3 \mathrm{Nt}$ - $\mathrm{m}$ machine load at the beginning and a $0.9 \mathrm{Nt}-\mathrm{m}$ machine load at 3 seconds in the 0.5 times nominal case of motor inertia and friction coefficient. (a) Rotor velocity response in simulation, (b) control signal response in simulation, (c) rotor velocity experiment response, and (d) control signal experiment response.

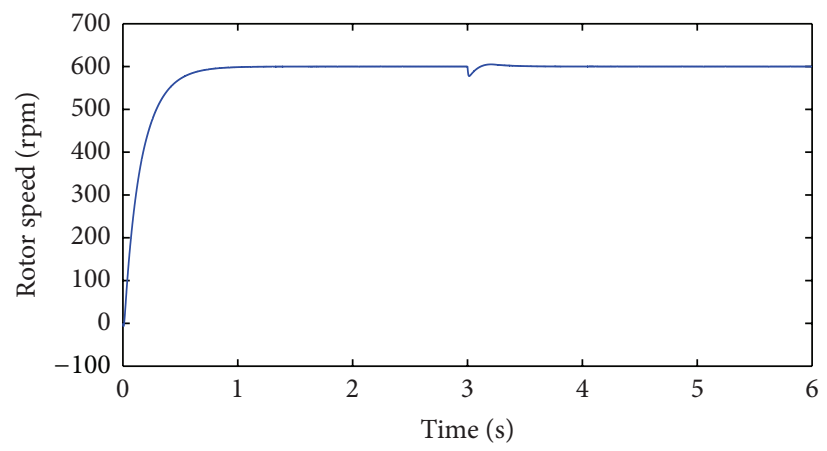

(a)

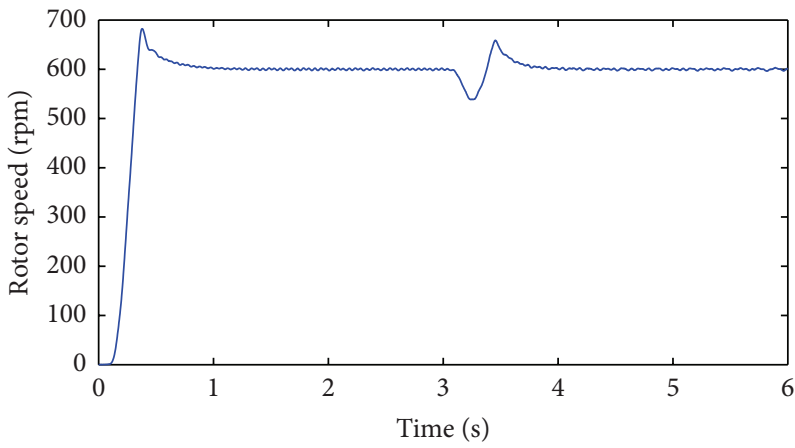

(c)

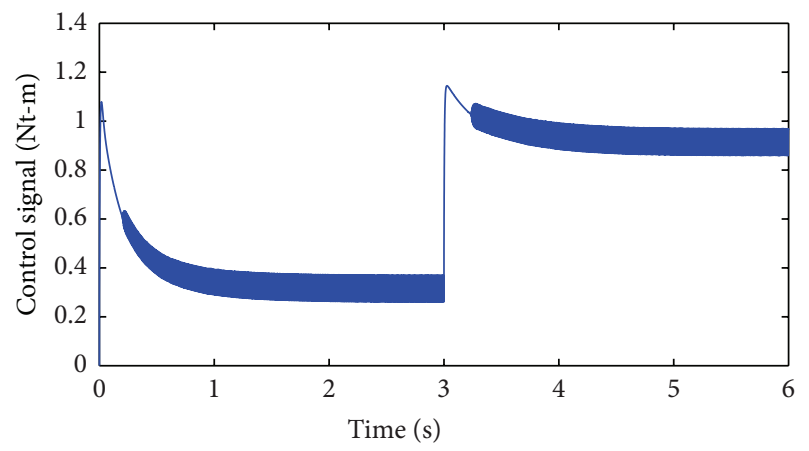

(b)

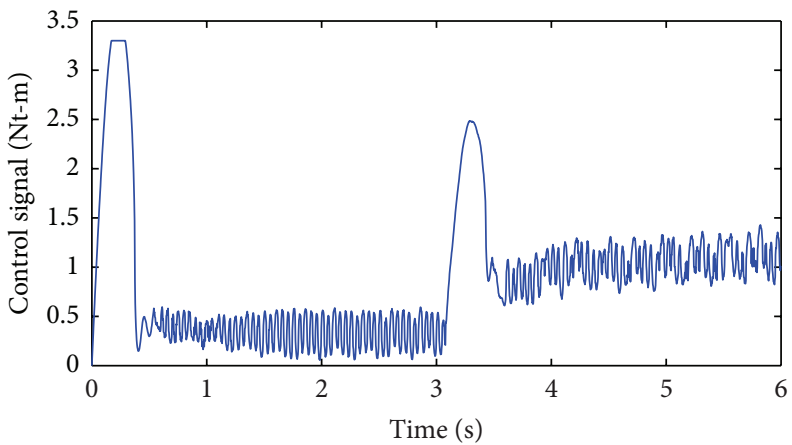

(d)

FIGURE 8: Experimental results of the super-twisting algorithm SOSMC for $\omega_{r}^{*}=600 \mathrm{rpm}$ under a $0.3 \mathrm{Nt}-\mathrm{m}$ machine load at the beginning and a $0.9 \mathrm{Nt}-\mathrm{m}$ machine load at 3 seconds in the 2 times nominal case of motor inertia and friction coefficient. (a) Rotor velocity response in simulation, (b) control signal response in simulation, (c) rotor velocity experiment response, and (d) control signal experiment response. 
the performance of the proposed controller. Compared with SMC controller, the proposed controller provides a faster and better response under parameter variation and external disturbances. The derived SOSMC laws are continuous and thus eliminate the chattering.

\section{Acknowledgments}

This work is supported by the National Science Council in Taiwan, through Grant NSC100-2221-E-224-002. The authors would like to acknowledge Mr. Yi-Chang Chang who constructed much of the hardware for the experimental system.

\section{References}

[1] T. Matsuo and T. A. Lipo, "Rotor design optimization of synchronous reluctance machine," IEEE Transactions on Energy Conversion, vol. 9, no. 2, pp. 359-365, 1994.

[2] A. Vagati, M. Pastorelli, and F. Scapino, "Impact of cross saturation in synchronous reluctance motors of the transverselaminated type," IEEE Transactions on Industry Applications, vol. 36, no. 4, pp. 1039-1046, 2000.

[3] N. Bianchi, S. Bolognani, D. Bon, and M. D. Pré, "Rotor flux-barrier design for torque ripple reduction in synchronous reluctance and PM-assisted synchronous reluctance motors," IEEE Transactions on Industry Applications, vol. 45, no. 3, pp. 921-928, 2009.

[4] J. H. Lee, I. K. Lee, Y. H. Cho, and T. W. Yun, "Characteristics analysis and optimum design of anisotropy rotor synchronous reluctance motor using coupled finite element method and response surface methodology," IEEE Transactions on Magnetics, vol. 45, no. 10, pp. 4696-4699, 2009.

[5] W.-H. Kim, K.-S. Kim, S.-J. Kim et al., "Optimal PM design of PMA-SynRM for wide constant-power operation and torque ripple reduction," IEEE Transactions on Magnetics, vol. 45, no. 10, pp. 4660-4663, 2009.

[6] J. Kolehmainen, "Synchronous reluctance motor with form blocked rotor," IEEE Transactions on Energy Conversion, vol. 25, no. 2, pp. 450-456, 2010.

[7] Y. S. Kim and I. H. Park, "Topology optimization of rotor in synchronous reluctance motor using level set method and shape design sensitivity," IEEE Transactions on Applied Superconductivity, vol. 20, no. 3, pp. 1093-1096, 2010.

[8] R. E. Betz, R. Lagerquist, M. Jovanovic, T. J. E. Miller, and R. H. Middleton, "Control of synchronous reluctance machines," IEEE Transactions on Industry Applications, vol. 29, no. 6, pp. 1110-1122, 1993.

[9] K.-K. Shyu and C.-K. Lai, "Incremental motion control of synchronous reluctance motor via multisegment sliding mode control method," IEEE Transactions on Control Systems Technology, vol. 10, no. 2, pp. 169-176, 2002.

[10] H. K. Chiang, C. H. Tseng, and W. L. Hsu, "Implementation of a sliding mode controller for synchronous reluctance motor drive considering core losses," Journal of the Chinese Institute of Engineers, vol. 25, no. 1, pp. 81-86, 2003.

[11] S. Chi, Z. Zhang, and L. Xu, "Sliding-mode sensorless control of direct-drive PM synchronous motors for washing machine applications," IEEE Transactions on Industry Applications, vol. 45, no. 2, pp. 582-590, 2009.

[12] Y.-S. Huang and C.-C. Sung, "Implementation of sliding mode controller for linear synchronous motors based on direct thrust control theory," IET Control Theory and Applications, vol. 4, no. 3, pp. 326-338, 2010.

[13] A. Levant, "Sliding order and sliding accuracy in sliding mode control," International Journal of Control, vol. 58, no. 6, pp. 1247$1263,1993$.

[14] S. Tong and H.-X. Li, "Fuzzy adaptive sliding-mode control for MIMO nonlinear systems," IEEE Transactions on Fuzzy Systems, vol. 11, no. 3, pp. 354-360, 2003.

[15] H.-X. Li and S. Tong, "A hybrid adaptive fuzzy control for a class of nonlinear MIMO systems," IEEE Transactions on Fuzzy Systems, vol. 11, no. 1, pp. 24-34, 2003.

[16] G. Bartolini, A. Ferrara, A. Levant, and E. Usai, "On second order sliding mode controllers," in Variable Structure Systems, Sliding Mode and Nonlinear Control, K. D. Young and U. Ozguner, Eds., vol. 247 of Lecture Notes in Control and Information Science, pp. 329-350, Springer, London, UK, 1999.

[17] M. Rashed, K. B. Goh, M. W. Dunnigan, P. F. A. MacConnell, A. F. Stronach, and B. W. Williams, "Sensorless second-order sliding-mode speed control of a voltage-fed induction-motor drive using nonlinear state feedback," IEE Proceedings on Electric Power Applications, vol. 152, no. 5, pp. 1127-1136, 2005.

[18] C. Kunusch, P. F. Puleston, M. A. Mayosky, and J. Riera, "Sliding mode strategy for PEM fuel cells stacks breathing control using a super-twisting algorithm," IEEE Transactions on Control Systems Technology, vol. 17, no. 1, pp. 167-174, 2009.

[19] C. Tournes and Y. Shtessel, "Automatic docking using second order sliding mode control," in Proceedings of the American Control Conference (ACC '07), pp. 3855-3860, New York, NY, USA, July 2007.

[20] C. Evangelista, P. Puleston, F. Valenciaga, and L. M. Fridman, "Lyapunov-designed super-twisting sliding mode control for wind energy conversion optimization," IEEE Transactions on Industrial Electronics, vol. 60, no. 2, pp. 538-5545, 2013.

[21] B. Koo, Y. Yoo, and S. Won, "Super-twisting algorithm-based sliding mode controller for a refrigeration system," in Proceeding of the 12th International Conference on Control, Automation and Systems (ICCAS '12), pp. 34-338, Jeju Island, Republic of Korea, October 2012.

[22] S. Di Gennaro, J. Rivera, and B. Castillo-Toledo, "Super-twisting sensorless control of permanent magnet synchronous motors," in Proceedings of the 49th IEEE Conference on Decision and Control (CDC '10), pp. 4018-4023, Atlanta, Ga, USA, December 2010.

[23] J. Machin, A. G. Loukianov, and J. M. Canedo, "Super-twisting sliding mode control of synchronous motors," in Proceeding of the 9th International Conference on Electrical Engineering, Computing Science and Automatic Control (CCE '12), pp. 1-6, Mexico City, Mexico, September 2012.

[24] A. Levant, "Universal single-input-single-output (SISO) sliding-mode controllers with finite-time convergence," IEEE Transactions on Automatic Control, vol. 46, no. 9, pp. 1447-1451, 2001.

[25] J. Davila, L. Fridman, and A. Levant, "Second-order slidingmode observer for mechanical systems," IEEE Transactions on Automatic Control, vol. 50, no. 11, pp. 1785-1789, 2005.

[26] J. A. Moreno and M. Osorio, "Strict Lyapunov functions for the super-twisting algorithm," IEEE Transactions on Automatic Control, vol. 57, no. 4, pp. 1035-1040, 2012.

[27] Y. Orlov, Y. Aoustin, and C. Chevallereau, "Finite time stabilization of a perturbed double integrator-part I: continuous sliding mode-based output feedback synthesis," IEEE Transactions on Automatic Control, vol. 56, no. 3, pp. 614-618, 2011. 
[28] A. Polyakov and A. Poznyak, "Lyapunov function design for finite-time convergence analysis: "Twisting" controller for second-order sliding mode realization," Automatica, vol. 45, no. 2, pp. 444-448, 2009.

[29] A. Polyakov and A. Poznyak, "Reaching time estimation for "super-twisting" second order sliding mode controller via Lyapunov function designing," IEEE Transactions on Automatic Control, vol. 54, no. 8, pp. 1951-1955, 2009.

[30] V. Utkin, "On convergence time and disturbance rejection of super-twisting control," IEEE Transactions on Automatic Control.

[31] M. Mohamadian, M. M. Pedram, and F. Ashrafzadeh, "Digital second order sliding mode control for a synchronous reluctance motor," in Proceedings of the IEEE Industry Applications Conference; 39th IAS Annual Meeting, pp. 1899-1902, Seattle, Wash, USA, October 2004.

[32] H. K. Chiang, W. B. Lin, C. Y. Chang, and C. A. Chen, "Supertwisting second order sliding mode control for a synchronous reluctance motor," in Proceedings of the 16th International Symposium on Artificial Life and Robotics (AROB '11), pp. 314317, Beppu, Japan, January 2011.

[33] T. Matsuo and T. A. Lipo, "Field oriented control of synchronous reluctance machine," in Proceedings of the IEEE 24th Annual Power Electronics Specialist Conference (PESC '93), pp. 425-431, June 1993.

[34] C.-A. Chen, W.-B. Lin, and H.-K. Chiang, "Design and implementation sliding mode controller based on radial basis function neural network for synchronous reluctance motor," in Proceedings of the 4th IEEE Conference on Industrial Electronics and Applications (ICIEA '09), pp. 281-286, Xi'an, China, May 2009.

[35] W.-B. Lin, C.-A. Chen, and H.-K. Chiang, "Design and implementation of a sliding mode controller using a Gaussian radial basis function neural network estimator for a synchronous reluctance motor speed drive," Electric Power Components and Systems, vol. 39, no. 6, pp. 548-562, 2011. 


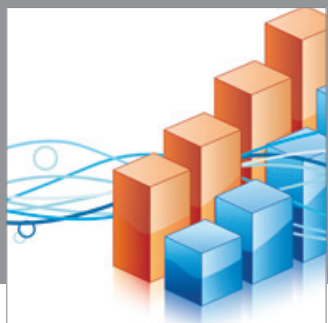

Advances in

Operations Research

mansans

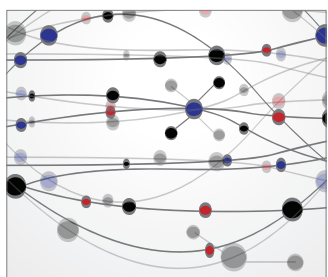

The Scientific World Journal
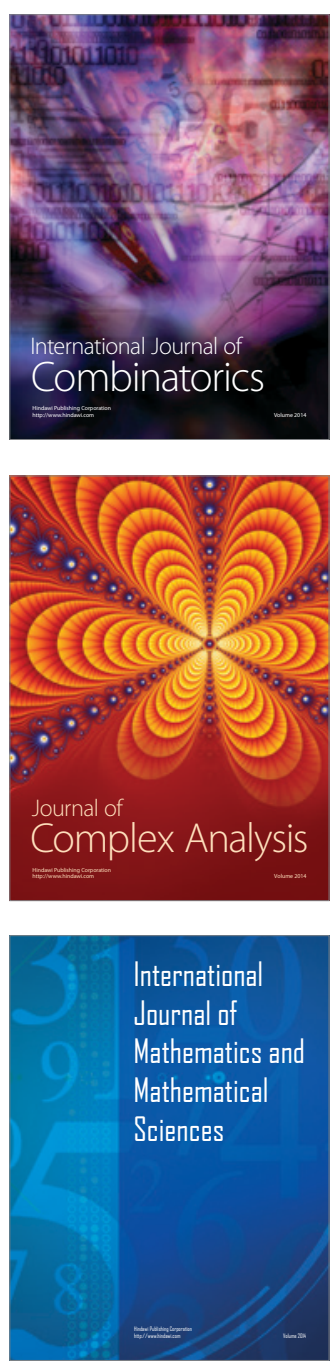
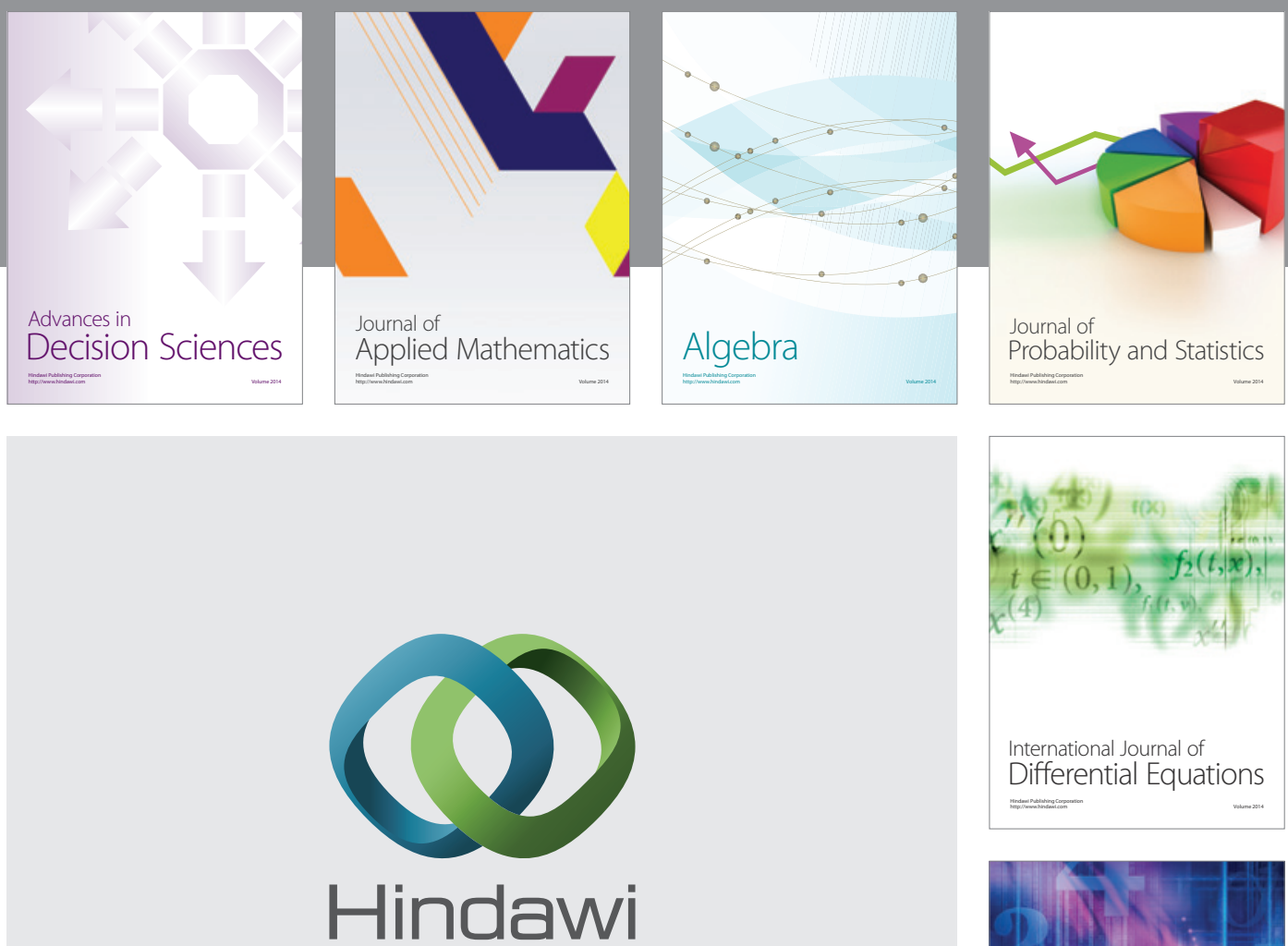

Submit your manuscripts at http://www.hindawi.com
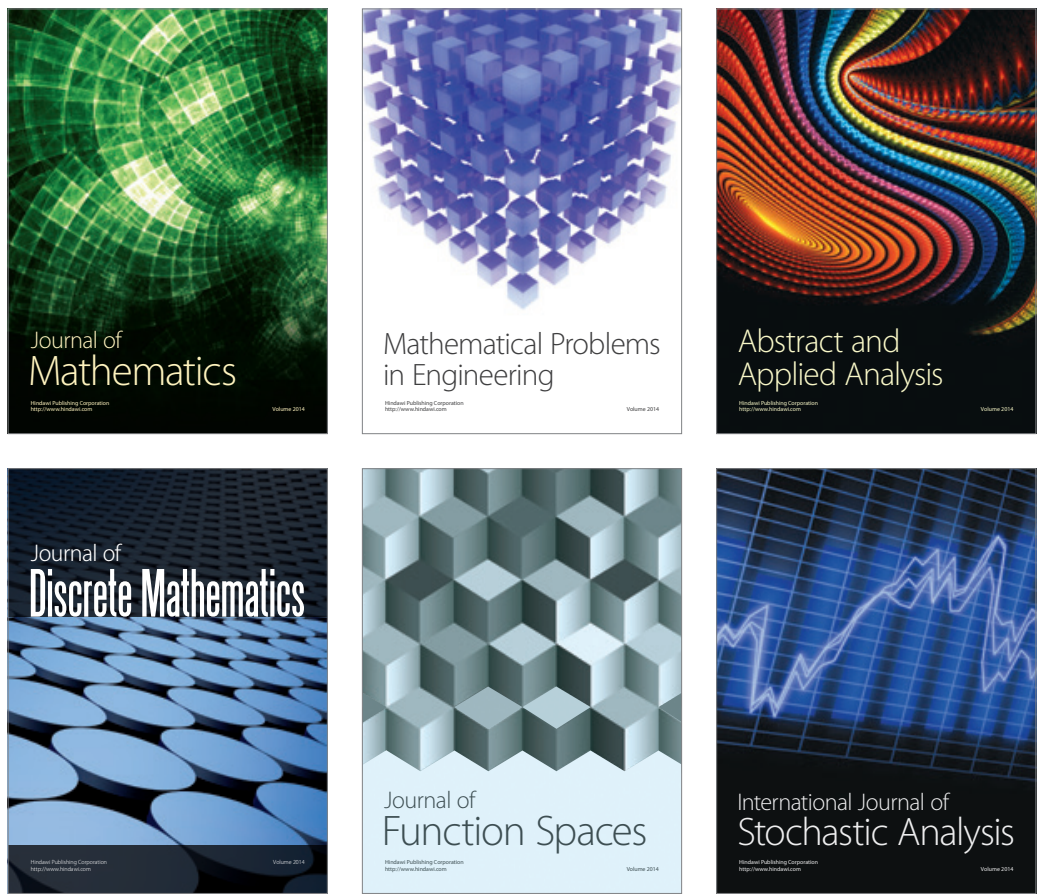

Journal of

Function Spaces

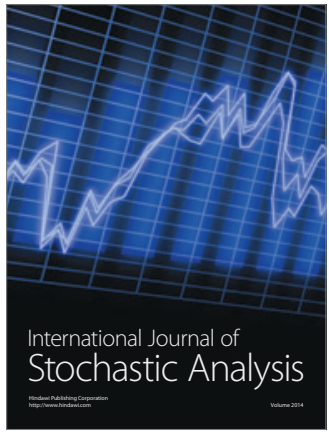

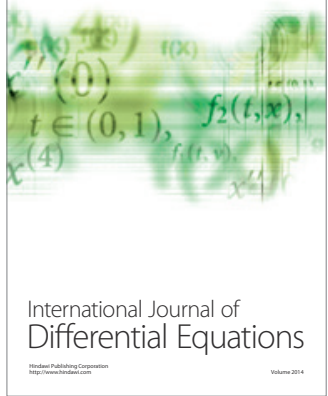
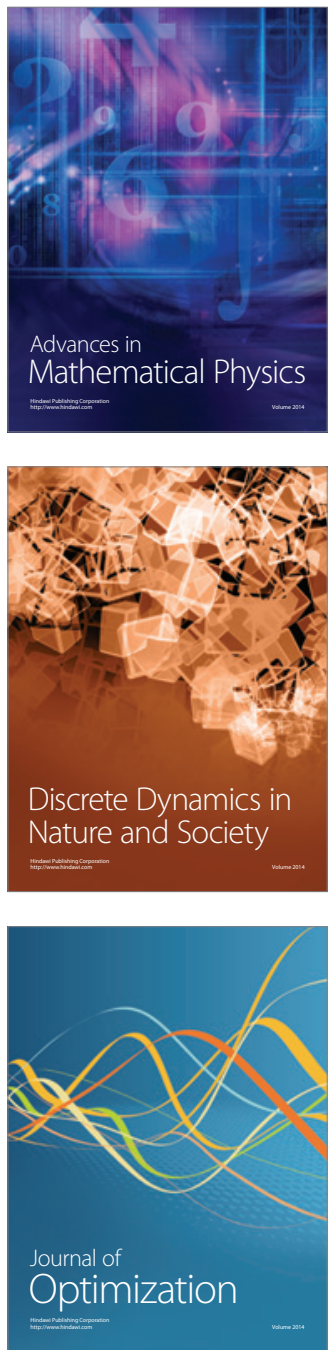